\title{
Treatment of Touggourt Wastewater by Bildet Omar Clay
}

\author{
Zineb Hacini ${ }^{1 *}$, Nassima Kafi ${ }^{1}$, Ibrahim Habib ${ }^{2}$ and Walid Bousseba ${ }^{1}$ \\ ${ }^{1}$ Laboratory of Water and Environment in Middle Sahara Ouargla, Université kasdi Merbah ouargla, Algeria \\ ${ }^{2}$ Université kasdi Merbah ouargla:Algeria/ National Research Centre, El-Tahrir Str., Dokki, Cairo, Egypt
}

\author{
DOI: $\underline{10.36348 / \mathrm{sijb} .2019 . \mathrm{v} 02 \mathrm{i} 11.002}$ \\ | Received: 28.06.2019 | Accepted: 07.07.2019| Published: 30.11.2019 \\ *Corresponding author: Hacini Zineb \\ Abstract
}

Water for human consumption may contain pollutants, so it needs to be treated. A natural clay, Bildet Omar bentonite (southern Algeria), was purified and characterized by calcination, pH-metry, IR, XRD and SEM. The results obtained showed that the clay has a conductance of $66.4 \mu \mathrm{S}$, a cation exchange capacity (CEC) of $0.91 \mathrm{meq} / \mathrm{g}$ and contains $12 \%$ of organic matter. Characterizations by IR, XRD and SEM showed that Maghnia bentonite (B) is composed of quartz as major impurity, illite $(7 \%)$ and mainly montmorillonite. This clay was saturated with sodium $(\mathrm{Na}+)$ and associated with iron (III), aluminum (III) and copper (II). The latter are inserted, by couple (Al-Cu, Fe-Cu and Fe-Al, $50-50 \%$ in atoms), in the inter-sheet space of the soda montmorillonite. The mass ratio metals / B is equal to 0.0625. The samples obtained are applied to fix the organic matter (MO) wastewater, very heavy, the city of Touggourt (southeastern Algeria). These organic materials represent $60 \%$ of suspended matter (MES). This work involves the study of urban wastewater treatment in the Touggourt town by natural processes. Water is used red and green clay from the region of Bildet Omar, it shows the importance of effective treatment of wastewater by clay. The results obtained show that:

- The best clarification is achieved with the use of clay

- Parallel treatment significantly reduces organic matter.

- The use of yellow clay leads to a better elimination of turbidity and organic matter.

Keywords: Treatment, Wastewater, Clay, Natural Process, Comparion. Copyright @ 2019: This is an open-access article distributed under the terms of the Creative Commons Attribution license which permits unrestricted
use, distribution, and reproduction in any medium for non-commercial use (NonCommercial, or CC-BY-NC) provided the original author and source
are credited.

\section{INTRODUCTION}

Water is a vital resource for man and his health and development, but because of increased consumption by individuals and pollution problems, it is caused mainly by the discharge of wastewater from the environment. In an anarchic and untreated way, those which contribute considerably to the contamination of the water table and the increase of its rise, one must obligatorily think of a purification of these waters. This is why, since ancient times, men have implemented sanitation systems in towns. The use of a local material, such as clay, for the treatment of waste water is promising technique for the purification of this water as a motion.

Experimental results by clay and comparison of results by two methods of treatment through measurement different pollution parameters namely: CE, COD, BOD5 and PO4-3. Finally a general conclusion reflecting the results of this work as well as some recommendations, punctuate our memory.
The objective of this work is the use of a simple and traditional method in the treatment of wastewater, it is used clay (Red and Green) as an absorbing and clarifying material so is for objective is the comparison of this method with the method of treatment of wastewater in the sewage treatment plant of the city Touggourt [1-3].

\section{MATERIALS AND METHOD \\ Sampling, Sampling and Analysis}

We take samples of course at the level of discharge, and as in our case, flows characterizing these releases are not the same size, the contribution of each point of discharge in terms of pollution is not identical.

In order to be able to present the samples the same day of the sampling in the laboratory, and view the dispersion of the localities (Figure-1).

Preparation of water and clay mixture Take a quantity of green clay and grind after:

- Rinse well with distilled water,

- Natural drying in the sun for 24 hours, 
- Place this quantity of dried clay in a container of glass and three times the amount of waste water in relation to the amount of clay, it consists of a mixture of two layers the clay at the bottom and the water at the top. (The same steps by contribution red clay.
- $\quad$ Analysis of this water for 21 days every 7 days sampled and analyzed.

- The glass container it consists of a drainage device; a tap mounted at the bottom of this container (Figure-2).

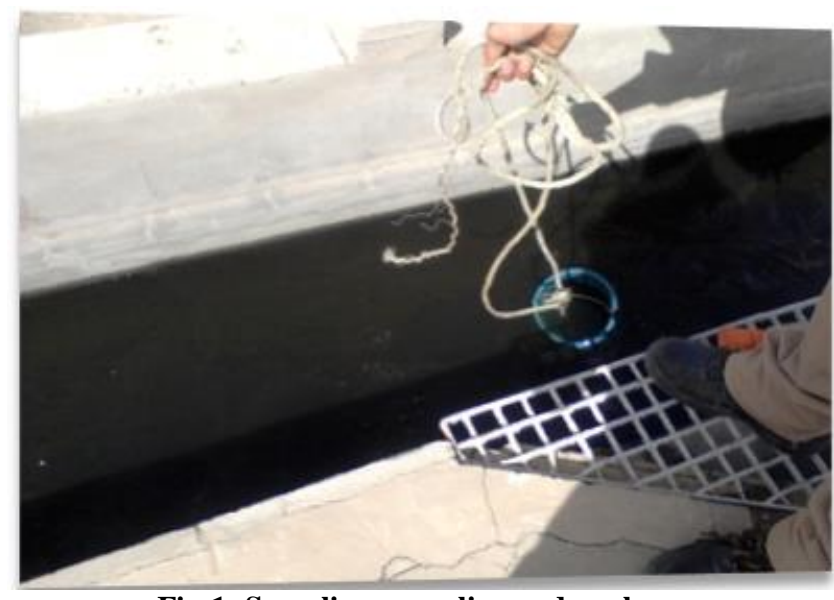

Fig-1: Sampling, sampling and analyzes

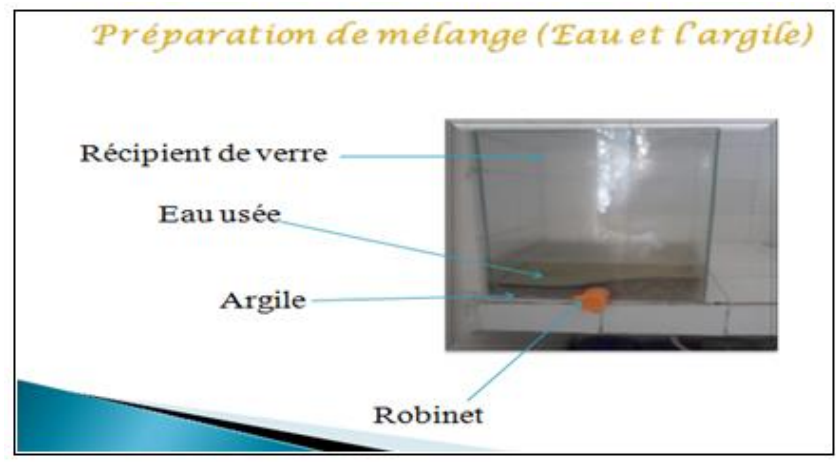

Fig-2: Preparation of water and clay mixture

\section{RESULTS AND DISCUSSION}

Water analyzes taken before clay treatment

To carry out this work, we used raw water from the SETP before the clay treatment.

\section{Water analyzes taken after treatment with clay}

The clay treatment during 21day every day we took a quantity of water and analyze. We use two types of green and red clay.

In the first week we notice a decrease in the pollutant load consisting mainly of suspended matter MES and increase of dissolved oxygen in the water treated by green clay compared to the treated water of red clay (Rasul), and translated in terms of DCO and $\mathrm{DBO}_{5} \mathrm{PO}^{-3}$.

In the second week we observe that an increase in the suspended matter; This is increased by the filtration method and the change in the measurement method of MES (using the capsule), the reduction of the pollutant load in terms of DCO and $\mathrm{DBO}_{5}$ and which results in an increase in the amount of dissolved oxygen following the bubbling operation such as $\mathrm{PO}^{-3}$ is successively decreased.

In the third week there is reduced term of DCO and $\mathrm{DBO}_{5}$ and $\mathrm{PO}^{-3}$ can be interpreted by the efficiency of the treatment operation for both types of clay, and an increase in the amount of dissolved oxygen.

The other parameters for the $\mathrm{pH}$ value is normal value for wastewater, the temperature is the ambient temperature The high conductivity that is leaching from the clay and the decrease in the last week almost almost total salts in the clay [4].

Overall the results of $\mathrm{DBO}_{5}$ and $\mathrm{DCO}$ and $\mathrm{PO}^{-3}$ are acceptable and reflect a good degradation, compared with the raw water, in addition to the fact that our effluent is considered as purely urban. Samples are analyzed the same day. sampling, this analysis is carried out at the laboratory of STEP Touggourt, ci analysis represent is the average of month may by raw water and water treat. The comparison of our results 
with the results obtained at the STEP (treated water) is admissible. This method of treatment is simple and effective method, inexpensive by the technique that uses in the STEP (Touggourt) but there is a long time, and does not add chemicals $[5,6]$.

Table-1: Analyzes after 21day

\begin{tabular}{|l|c|c|}
\hline \multirow{2}{*}{ The settings } & \multicolumn{2}{|c|}{ Sample to be processed by } \\
\cline { 2 - 3 } & Green clay & Red clay (rassoul) \\
\hline $\mathrm{pH}$ & 7.65 & 7.73 \\
\hline $\mathrm{CE}(\mathrm{ms} / \mathrm{cm})$ & 20.09 & 23.1 \\
\hline $\mathrm{O}_{2}$ diss $(\mathrm{mg} / \mathrm{l})$ & 5.34 & 7.48 \\
\hline $\mathrm{T}^{\circ} \mathrm{C}$ & 21.2 & 21.9 \\
\hline $\mathrm{MES}(\mathrm{mg} / \mathrm{l})$ & $/$ & $/$ \\
\hline $\mathrm{DBO}(\mathrm{mg} / \mathrm{l})$ & 92 & 63.04 \\
\hline $\mathrm{DCO}(\mathrm{mg} / \mathrm{l})$ & 115 & 78.8 \\
\hline $\mathrm{PO}_{4}^{-3}(\mathrm{mg} / \mathrm{l})$ & 0.217 & 0.575 \\
\hline
\end{tabular}

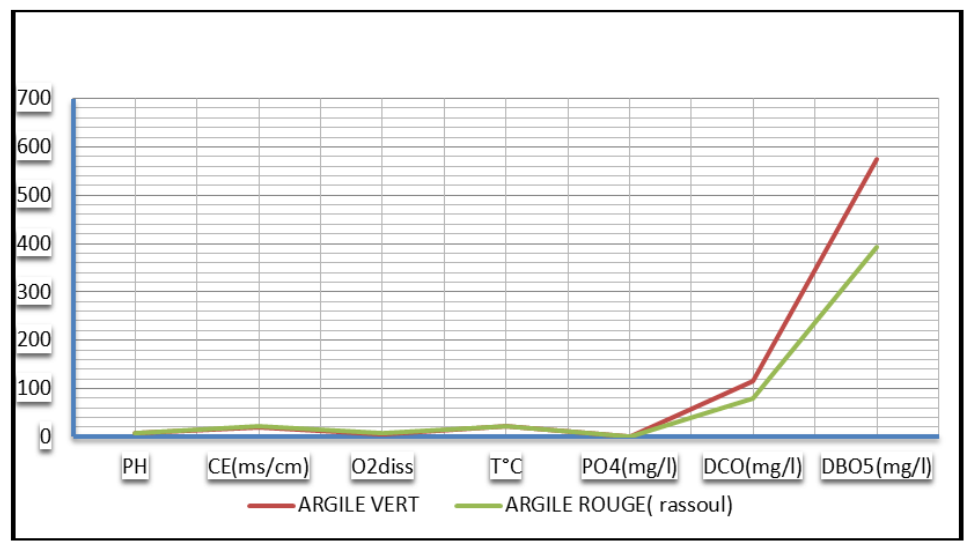

Fig-3: Physico-chemical analysis curve of the water to be treated with clay after 21 days

\section{CONCLUSION}

From our work we can draw that the use of clays, can be seriously considered to solve the problem of wastewater without resorting to very expensive techniques and which require very important means of management and maintenance.

The experimental device that we have proposed, consists of a glass container containing a fixed bed (clay), gave satisfactory results. These showed an elimination efficiency of organic matter, obtained for $\mathrm{DCO}$ and $\mathrm{DBO}_{5}$ respectively. Compared to the technique used in the STEP Like any laboratory work, we recommend a continuity of this work taking into consideration the following points:

- Look for the influence of each physicochemical parameter.

- Characterization of filter materials.

- Deepen the work by studying other multilayer layer models in local materials to refine the treatment model that could be used in the fight against effluent pollution.

\section{ACKNOWLEDGEMENTS}

We are grateful to Prof. Bebba Ahmed, Department of Chemistry, University of KasdiMerbah, Ouargla,Algeriaor helpful discussions. Zineb Hacini thanks Mr.Boukhari Fouad and BoussebraWalid for their help during reduction steps.

\section{REFERENCES}

1. AIPEA. (1996). (Association Internationale Pour l'Etude des Argiles), Newsletter $n^{\circ} 32$.

2. Bouchet, A., Meunier, A., \& Sardini, P. (2000). Minéraux argileux: structure cristalline, identification par diffraction de rayons $X$ (Vol. 23). Editions Elf Exploration.

3. Caillère, S., Hénin, S., \& Rautureau, M. (1982). Minéralogie des argiles: Classification et nomenclature (p. 182). Masson.

4. Luckham, P. F., \& Rossi, S. (1999). The colloidal and rheological properties of bentonite suspensions. Advances in colloid and interface science, 82(1-3), 43-92.

5. Yildiz, N., Sarikaya, Y., \& Calimli, A. (1999). The effect of the electrolyte concentration and $\mathrm{pH}$ on the rheological properties of the original and the Na2CO3-activated Kütahya bentonite. Applied Clay Science, 14(5-6), 319-327.

6. Komadel, P., Schmidt, D., Madejová, J., \& Č́ícel, B. (1990). Alteration of smectites by treatments with hydrochloric acid and sodium carbonate solutions. Applied Clay Science, 5(2), 113-122. 